\title{
CONHECIMENTOS E EXPECTATIVAS DE ADOLESCENTES NULIGESTAS ACERCA DO PARTO
}

\author{
Fátima Raquel Rosado Morais \\ Tatiana Paiva Nunes \\ Renata Meira Veras \\ Luciana Fernandes de Medeiros Azevedo ${ }^{\infty}$
}

\begin{abstract}
RESUMO. Este estudo objetivou apreender os conhecimentos de adolescentes nuligestas acerca do parto e do nascimento, mediante uma pesquisa qualitativa com doze adolescentes de idade entre 12 e 16 anos, residentes na área de uma unidade de saúde de Mossoró - RN. Os resultados mostraram que as adolescentes possuem conhecimentos precários acerca do parto, sendo as informações permeadas por mitos e desarticuladas de conceitos capazes de transformar os saberes vigentes. Assim, evidencia-se a necessidade da aproximação das adolescentes com a temática da sexualidade, e em particular, da gravidez e parto, para que possam analisar e escolher a forma ideal de parir, identificando possibilidades para um parto mais humanizado e saudável. Para isto, sugere-se que os profissionais de saúde, em especial os enfermeiros, desenvolvam atividades socioeducativas de preparação para o parto em articulação com a escola e a família, com vista a esclarecer as adolescentes quanto à dinâmica da parturição e assim contribuir para a desmistificação de estigmas ainda presentes na sociedade.
\end{abstract}

Palavras-chave: Adolescência; gravidez; parto.

\section{KNOWLEDGE AND EXPECTATIONS OF NULLIPAROUS ADOLESCENTS ABOUT CHILDBIRTH}

\begin{abstract}
This study aimed to clarify the nulliparous teenager's knowledge about the work labor and the birth. It was realized a qualitative research with twelve teenagers, between 12 and 16 years old, who lived around a Health Unit in Mossoró-RN. The results showed that the teenagers have lack of knowledge about the work labor, and the information was permeated by myths and it shows an unarticulated concepts that can transform existing knowledge. Therefore, it is highlighted the need of connecting the teenagers with the sexuality issue, particularly with work labor and pregnancy. It is necessary to allow the teenagers to analyze and decide about the best way to have babies, identifying possibilities to a humanized and healthier work labor. Thus, it is imperative that the health workers, specially the nurses, should develop socioeducated activities introducing the knowledge about the work labor linked with school and family. This can develop the empowerment process into teenagers about the best work labor type, contributing to eliminate the stigmas about the sexuality and work labor in the society.
\end{abstract}

Key words: Adolescence; pregnancy; labor (childbirth).

\section{CONOCIMIENTO Y EXPECTATIVAS DE PARTO DE ADOLESCENTES NULÍPARAS}

RESUMEN. Estudio tuvo como objetivo capturar el conocimiento de nulíparas adolescentes sobre el trabajo y el parto, una investigación cualitativa que se llevó a cabo con doce adolescentes de 12 a 16 años, residentes en la zona de una Unidad de Salud en Mossoró-RN. Los resultados mostraron que los adolescentes tienen escasos conocimientos sobre el parto, y la información estaba impregnada de mitos y conceptos inconexos que puede transformar el conocimiento existente. Por lo tanto, plantea la necesidad de abordar el tema de los adolescentes con la sexualidad, el embarazo y en particular, y el parto, para que puedan analizar y elegir la

\footnotetext{
Doutora em Psicologia (Psicologia Social) pela Universidade Federal do Rio Grande do Norte. Professora do Programa de PósGraduação em Saúde e Sociedade da Universidade do Estado do Rio Grande do Norte.

\# Enfermeira pela Universidade do Estado do Rio Grande do Norte.

II Doutora em Psicologia (Psicologia Social) pela Universidade Federal do Rio Grande do Norte. Professora do Programa de PósGraduação em Estudos Interdiciplinares da Universidade Federal da Bahia.

x Doutora em Psicologia (Psicologia Social) pela Universidade Federal do Rio Grande do Norte. Professora dos cursos de psicologia da Unifacex e Uni-RN.
} 
forma ideal de dar a luz, identificar las posibilidades de un parto más humano y saludable. Por lo tanto, se sugiere que los profesionales de la salud, especialmente las enfermeras, para desarrollar actividades sociales y educativas, preparación para el parto, en coordinación con la escuela y la familia, la creación de claros en la dinámica de la maternidad adolescente, contribuyendo a la desmitificación de los estigmas siguen presentes en la sociedad.

Palabras-clave: Adolescencia; embarazo; parto.

Desde a década de 1970 houve um aumento significativo na proporção de nascimentos por partos cesáreos em todas as regiões do Brasil e isso tem se constituído em um grave problema na área de saúde pública (Mandarino, 2008). Segundo dados do Ministério da Saúde, a cesariana já representa $43 \%$ dos partos realizados no Brasil nos setores público e privado. Quando se leva em consideração o tipo da assistência recebida, percebe-se que os planos de saúde privados são responsáveis por $80 \%$ dos partos cesáreos (Weinfurter, 2008).

A análise do tipo de parto realizado reflete as práticas obstétricas no Brasil, especificamente no que concerne à evolução dos partos cesáreos. As cesáreas aumentam a probabilidade de morbimortalidade materna e neonatal, destacando-se como causas a infecção puerperal e a prematuridade. Também se associam com um retardo na recuperação puerperal, maior tempo de internação e, consequentemente, maior necessidade de assistência por profissionais de saúde, maior uso de medicamentos e início tardio da amamentação (D'Orsi et al., 2006).

Assim, atenta aos riscos tanto para a mãe quanto para a criança do parto cesáreo, a Organização Mundial de Saúde [OMS] (1996) recomenda o percentual máximo de $15 \%$ do total de partos por cirurgia cesárea. As cesarianas só deveriam ocorrer em situações em que a mulher ou o bebê estivessem em risco, não havendo possibilidades de evolução para um parto vaginal/normal. Apesar, porém, da recomendação da OMS, percebe-se um grande percentual de partos cesáreos no Brasil, despertando críticas no próprio campo biomédico. O excessivo intervencionismo e os riscos associados a esse tipo de parto sugerem a necessidade de refletir sobre as práticas vigentes no processo de parturição.

A "medicalização" do parto, ou seja, a mudança de assistência baseada na plausível segurança dos procedimentos médicos intervencionistas transformou o parto normal em uma situação de risco. Assim, a tecnologia médica se apresenta como uma resposta necessária para o controle dos riscos, justificando a legitimação social do parto cesáreo como um procedimento seguro, indolor, moderno e ideal para qualquer grávida (Mandarino 2008; Tesser, 2010). Isto leva à constatação de que a maioria das maternidades persiste em aplicar um modelo em que os interesses institucionais se sobrepõem às necessidades reais da parturiente.

Obre essa questão, além das questões institucionais e dos interesses biomédicos, existe um longo histórico de medicalização do corpo, inclusive o feminino (Vieira, 2002). No século XIX o papel da parteira já era questionado pela medicina e foram então criadas as primeiras maternidades com assistência médica. Enquanto antes o parto era realizado em casa, com a assistência de uma parteira, ao longo do século XX identificamos o gradativo aumento de hospitais e maternidades preparados para realizá-lo. A mulher passa a ter menos controle sobre o seu corpo e o parto passa a ser objeto de intervenção médica tal como uma doença qualquer.

$\mathrm{Na}$ atualidade, a maioria das mulheres, sobretudo as das classes mais abastadas, tem medo do parto vaginal por causa da dor, divulgada amplamente e, muitas vezes, de forma exagerada em filmes, novelas e outros meios de comunicação. Há inclusive um discurso socialmente aceito entre as mulheres de que o parto cesáreo é menos doloroso do que o parto normal.

Nesse contexto, surge, em nível mundial, a discussão em busca de uma maternidade segura, que objetiva resgatar práticas mais naturais para esse processo, visando reduzir intercorrências maternas e neonatais (OMS, 1996). No Brasil, essas ideias ganharam contornos de humanização para o parto e nascimento, passando este tema a ser o norte para a dinâmica de trabalho nos serviços de atenção à saúde da mulher (Ministério da Saúde, 2002; 2004).

Devido a um percurso histórico-biomédico marcado pela medicalização intervencionista e, muitas vezes, iatrogênica, ainda existem na sociedade contemporânea entraves que dificultam a adesão da mulher ao parto normal. Entre esses entraves podemse citar os mitos e tabus construídos sobre o processo de parturição, a falta de informação quanto aos diferentes tipos de parto, o processo de formação em saúde que ainda tende a privilegiar os aspectos biológicos, com uma prática intervencionista para a dinâmica do parto, e as condições dos serviços oferecidos à população assistida pelo Sistema Único de Saúde (SUS), entre outros (Merighi \& Gualda, 2009; Morais, 2010; Wrobel \& Ribeiro, 2006). 
Nesse contexto, torna-se imprescindível que a mulher tome os devidos conhecimentos e tenha maior espaço de discussão quanto às alterações que acontecerão no seu corpo durante cada tipo de parto. A aquisição de informações precisas sobre as alterações físicas e emocionais e sobre o processo de parturição tende a facilitar a tranquilidade neste momento e torná-la mais receptiva ao processo fisiológico que se desenrola no seu corpo (Ministério da Saúde, 2001; Sodré, Bonadio, Jesus, \& Merighi, 2010).

Dessa forma, a compreensão da diversidade de fatores que interferem na assistência ao parto, culminando nas taxas elevadas de cesarianas, ainda carece de consenso na proposição de soluções para o controle dessas taxas. Sabe-se que os programas socioeducacionais referentes à educação e planejamento familiar geralmente não possuem eficácia, em vista da desconexão entre as necessidades de conhecimento das futuras mães e o conteúdo proposto, primordialmente através de palestras. $\mathrm{Na}$ verdade, não basta apenas o conhecimento, mas é necessária a desconstrução de um medo que foi instituído socioculturalmente ao longo do século XX, contribuindo para a rejeição das mulheres ao parto normal. De acordo com Helman (2009, p.170), "as definições do que constitui uma dor anormal e que, portanto, requer atenção médica e tratamento tendem a ser definidas culturalmente e a variar com tempo". Verifica-se que a dor do parto passou a ser considerada anormal e insuportável. Nesse sentido, as mulheres não querem mais sentir dor e isso também contribui para o aumento do número de cesáreas.

Igualmente, sabe-se que as construções e representações de gênero são essenciais para dar sentido aos comportamentos sexuais e reprodutivos, inclusive uma eventual gravidez e parentalidade na adolescência (Heilborn et al., 2002). Apesar de se ter observado no Brasil um pequeno declínio em relação ao número de nascimentos oriundos de mães até os 19 anos (de 22,5 em 2000 para 20,6 em 2006), este índice ainda é elevado em comparação aos países desenvolvidos (Ministério da Saúde, 2009). Existem inúmeros aspectos sociais, culturais e econômicos que influenciam a gravidez na adolescência, fato que precisaria ser levado em conta nas ações educativas propostas pelo Ministério da Saúde e pelo SUS.

Diante disso, assume grande importância uma análise dos conhecimentos de adolescentes que nunca engravidaram (nuligestas) acerca do parto e nascimento. Esse tipo de análise representa uma oportunidade para identificar de que forma os saberes prévios das adolescentes são formados e como podem influenciar na forma como vão lidar com o processo de gravidez e nascimento. Nesse sentido, espera-se com este estudo contribuir para a construção de propostas práticas que possibilitem a otimização dos programas sociais dirigidos a essa faixa etária.

\section{METODOLOGIA}

Para atender aos objetivos da pesquisa, foi realizado um estudo qualitativo em que as entrevistas semiestruturadas foram utilizadas como a técnica principal. O campo de estudo escolhido engloba a área de abrangência da Unidade Básica de Saúde (UBS) Dr. Chico Costa, localizada no bairro Santo Antônio, no município de Mossoró - RN. A escolha dessa área geográfica aconteceu em virtude de esse ser um dos bairros mais populosos da cidade e ainda contar com diversos problemas de ordem estrutural e econômica, pela carência social dos moradores da localidade.

A população da pesquisa foi constituída por adolescentes não grávidas residentes na comunidade. Os critérios de inclusão para delimitação da amostra foram: ser adolescente na faixa etária compreendida entre 12 e 16 anos; não estar grávida, nem nunca ter engravidado; e aceitar participar da pesquisa com o consentimento e assinatura do pai/mãe ou responsável.

Como na UBS analisada nesse estudo não existem ações específicas para o grupo de adolescentes, para buscar participantes foram realizadas visitas com os agentes comunitários de saúde (ACS) às casas em que viviam adolescentes que atendiam aos critérios estabelecidos. Assim, após autorização prévia do responsável, as entrevistas foram agendadas e realizadas em um espaço reservado nas residências das participantes.

A delimitação da amostra aconteceu com base na saturação dos discursos, pois quando as respostas começaram a se repetir a amostra foi caracterizada como ideal e deu-se por encerrada a pesquisa empírica (Fontanella, Ricas \& Turatto, 2008). Com este critério, o grupo do estudo ficou constituído por 12 (doze) adolescentes.

A coleta de dados foi realizada mediante um roteiro de entrevista com questões norteadoras que abordavam aspectos relacionados aos conhecimentos referentes aos tipos de parto e às expectativas quanto às formas de parir. As entrevistas foram gravadas e, após as transcrições, foram realizadas leituras sucessivas com o objetivo de reconhecer as construções discursivas e de sentido que emergiam do material. 
As construções identificadas foram analisadas à luz do referencial teórico em estudo na perspectiva de compreender os conhecimentos, anseios e expectativas das adolescentes não grávidas sobre as formas de parir e nascer, contribuindo para a desmistificação do parto no imaginário cultural das adolescentes.

Cabe salientar que a pesquisa foi submetida ao Comitê de Ética em Pesquisa da Universidade do Estado do Rio Grande do Norte (CEP-UERN), sob o CAAE n. ${ }^{\circ}$ 5091.0.000.428-09, tendo parecer favorável sob o número 070/09.

\section{ANÁLISE E DISCUSSÃO DOS RESULTADOS}

Discutir acerca dos conhecimentos das formas de parir entre adolescentes não grávidas tende a ser um divisor entre o que costumeiramente se pensa e o que nunca se buscou como objeto de reflexão. Assim, da análise dos dados obtidos a partir das entrevistas foi possível desenvolver três construções discursivas: 1) Conhecimentos sobre as formas de parir e nascer; 2) Fontes de informações sobre gestação e parto; e 3) Expectativas de adolescentes sobre as formas de parir. A seguir, apresenta-se a discussão sobre cada uma delas.

\section{Conhecimentos sobre as formas de parir e nascer}

Sabe-se que a escolha da forma de parir sofre influências culturais e biomédicas que podem determinar a alta preferência por um tipo de parto, no caso do Brasil, o parto cesáreo. Essas influências culturais são determinadas, principalmente, pelas relações de poder dos profissionais de saúde perpetuadas pela hegemonia biomédica (Surtees, 2010; Lupton, 1997; Vieira, 2002).

$\mathrm{Na}$ análise dos discursos das adolescentes acerca das formas de parir e nascer percebeu-se que elas possuíam um conhecimento limitado sobre o assunto, restringindo-se a conhecer as duas formas de o bebê sair, ou seja, pela vagina ou mediante cirurgia: "Cesáreo eu acho que é uma cirurgia. E, normal, é normal." (Adolescente 1) "No parto normal o bebê sai pela vagina. No cirúrgico é uma cirurgia." (Adolescente 2) "O cesáreo é quando a mulher não pode ter pela vagina, aí tem que cortar." (Adolescente 3) "É tipo uma cirurgia. E o normal é pela vagina." (Adolescente 5 )

Esses relatos configuram apenas o conhecimento básico por parte das adolescentes sobre o processo do parto, sua fisiologia, os principais procedimentos, e a indicação de cesárea. O pouco conhecimento das adolescentes acerca do processo básico fisiológico inerente ao parto pode determinar a subordinação das mulheres à escolha do tipo de parto pelo qual o médico faz opção. Isso pode fazer com que elas percam o controle sobre o processo da gravidez, parto e puerpério, o que reforça a ideia de medicalização do corpo feminino e deixa a mulher à mercê das escolhas do médico (Vieira, 2002). A medicalização do parto pode acontecer tanto em função da confiança depositada na figura do médico quanto pelo pouco conhecimento das mulheres sobre seus processos corporais (Gama, Giffin, Ângulo-Tuesta, Barbosa, \& D’Orsi, 2009).

Sabe-se que o discurso biomédico sobre a forma de parir tem influência nas decisões da sociedade. Esse discurso justificador e normatizado dos comportamentos reprodutivos adquire uma dimensão difícil de ser enfrentada pelas mulheres, restando a elas o papel passivo de aceitar as decisões sobre seu próprio corpo. O estudo de Barbosa, Giffin, ÂnguloTuesta, Chor, D’Orsi, \& Reis (2003) confirmou que a maioria das mulheres pesquisadas não queria ter um parto cesáreo, no entanto a decisão final coube à equipe médica.

A humanização do parto e nascimento propõe a desmedicalização e práticas naturais para esse momento, porém essa ideia precisa ser construída no imaginário dos diferentes atores, em distintos ciclos de vida, na perspectiva de gerar mudanças efetivas. A atuação educativa de grupos organizados da sociedade - profissionais e mulheres - poderia tornar as mulheres sujeitos de sua saúde, alterando a relação de poder desigual entre médico e paciente. Por isso é imprescindível atuar desde a base, a partir da formação da cidadania, ajudando a construir novos conceitos que, consequentemente, tenderão a gerar outras práticas futuras (Ministério da Saúde, 2002).

Por outro lado, percebeu-se pelos relatos das adolescentes que as informações sobre a gravidez e tipo de parto tendem a ser compartilhadas apenas no momento em que a mulher engravida, ficando todo o período anterior à gravidez numa dimensão não valorizada. Diante disso, ressalta-se a necessidade de criar adaptar as políticas públicas de planejamento familiar para o público jovem e de refletir acerca da gestação como um processo que se desenvolve desde a juventude, nas primeiras noções de família, e das formas de se ter um filho.

$\mathrm{O}$ conhecimento inadequado e os mitos e crenças criados em torno do parto podem refletir o modo como o assunto é tratado na sociedade. Isto demanda um aprofundamento do tema, com indagações sobre as fontes de informação acerca das formas de parir. 


\section{Fonte de informações sobre as formas de parir e nascer}

Como a aquisição dos conhecimentos e saberes acerca da gestação e do parto se configura a partir de um processo sócio-histórico, é fundamental conhecer não apenas como as informações sobre esta temática são compreendidas, mas também de que forma chegam às adolescentes. Questionadas acerca da fonte de informações sobre o parto, as participantes apontaram que, apesar de pouco conversarem sobre esse assunto, em geral, os principais canais de informação são a família - especialmente a mãe -, a escola e as amigas:

\begin{abstract}
"Eu nunca converso com ninguém sobre esse negócio de gravidez não... Só com mainha que diz: não pegue menino, use camisinha! Pronto, é só isso que ela diz." (Adolescente 4) "Com a minha mãe. Perguntei sobre o meu parto e do meu irmão, aí ela falou que o normal não tinha cirurgia e no cesáreo tem cirurgia." (Adolescente 5).
\end{abstract}

É normal que os familiares, em especial as mães, se preocupem com os aspectos relacionados à sexualidade das filhas; porém as orientações tendem a ser superficiais, não sendo abordados os conteúdos necessários à discussão dessa temática nessa faixa etária. Isso provavelmente se deva ao fato de que muitas mães também não possuem conhecimento adequado para tratar de assuntos dessa dimensão, e assim acabam reprimindo a filha e impondo-lhe o que deve ou não fazer (Almeida, 2008), quando se sabe que discursos opressores, ao invés de educar, acabam favorecendo um maior distanciamento entre os adolescentes e seus responsáveis.

Essas atitudes podem ter relação com o fato de as mães entenderem que conversar com suas filhas sobre sexualidade pode incentivá-las ao sexo, assunto que é polêmico para a família (Fuchs, 2007). Sobre isso, Maia (1998, p. 50) argumenta que "os pais, e especialmente as mães, são veículos de informações limitadas porque tentam proteger as filhas contra o mal [...]. Em geral, ameaçam com relação à perda da virgindade". Nesse caso, seria interessante uma política de educação sexual nas escolas, começando com a participação dos pais para discutirem melhor esse processo. É preciso desconstruir essa ideia de que pouca informação é melhor para a criança e o adolescente. As informações estão presentes o tempo todo, seja na mídia, seja na escola. O papel dos pais é trabalhar essa informação da forma mais adequada possível, e não evitar o contato do filho com esses saberes.

Por outro lado, algumas adolescentes afirmaram que não conversam com seus pais sobre este assunto e que geralmente entram em contato com estas informações por meio de algumas atividades desenvolvidas na escola: "Nunca falei com ninguém. Às vezes tem palestra no colégio, mas nunca entram em detalhes não, só falam que deve se prevenir, usar camisinha." (Adolescente 6)

Reconhece-se que, além da família, a escola deve ser uma das protagonistas no processo de orientação sexual dos adolescentes; porém, como se pode ver, esta instituição geralmente tende a realizar ações pontuais, por meio de palestras e vídeos, os quais abordam com mais especificidade os aspectos científicos e biológicos referentes à sexualidade (Biscoli, Favarão, Feiten, Souza, \& Perpétuo, 2005). Do mesmo modo que a família aborda esse tema de forma superficial, a escola também o faz, restringindose à apresentação dos métodos anticoncepcionais e preocupando-se apenas em transmitir o conhecimento de que é necessário fazer sexo seguro, com uso de camisinha como forma de prevenir uma gravidez indesejada. Neste sentido, a informação é passada, mas não debatida, refletida e ressignificada, e isto cria uma relação verticalizada entre a instituição (familiar ou escolar) e o jovem adolescente, que apenas recebe a informação, sem maiores discussões. Este modo de proceder não é suficiente para mudar concepções e crenças acerca da gravidez e do parto.

Ademais, o conhecimento básico acerca dos tipos de parto e o incentivo à reflexão por parte dos adolescentes sobre esse assunto não é estimulado nas escolas. Menos ainda se busca articular estes conhecimentos com o cotidiano dos jovens, na tentativa de favorecer um pensamento crítico, para que estes possam refletir no seu dia a dia colocar em prática os novos saberes. Então, carentes de informações por parte da família e da escola, as adolescentes tendem a adquirir conhecimentos através de outras pessoas. Em meio às conversas informais com as colegas, elas acabam trocando informações, mesmo que estas não sejam as mais adequadas, como se vê nas falas a seguir.

"Converso com minha amiga. Ela não sabia como os bebês nasciam, aí eu peguei e disse. Aí depois ela se lembrou que a mãe dela disse que bota um pano nas pernas e puxa o bebê." (Adolescente 7) "Minhas amigas me perguntam: "Ah, qual é o melhor o normal ou 
o cesáreo? Qual o melhor no caso da dor, né?" (adolescente 9).

É sabido que o diálogo é frequente e comum entre as adolescentes, porém não é suficiente, uma vez que se percebem questionamentos das participantes referentes ao parto, reforçando a carência de orientação sobre o assunto. A desinformação e a falta de diálogo em outros espaços levam as adolescentes a se informarem com colegas, quase sempre tão pouco conhecedoras quanto elas mesmas, o que persistires as incertezas, que apenas parcialmente são esclarecidas. $\mathrm{Na}$ fala de uma das participantes é possível identificar o mito em relação à dor do parto. Essa dor foi valorizada de tal forma que deixou de ser fisiológica e passou a ser completamente temida. Isto contribui para que estas jovens não sejam suficientemente preparadas para o enfrentamento de situações futuras, ou até mesmo, desenvolvam sua sexualidade de modo inadequado (Borges, Nichiata, \& Schor, 2006).

De acordo com uma pesquisa realizada por Costa, Figueiredo, Pacheco, \& Pais (2003), a maioria das puérperas analisadas (72\%) não possuía conhecimentos acerca de nenhum tipo de parto. Dessa forma, o estudo desses pesquisadores confirmou que existe relação entre a falta de informação e de participação nas decisões acerca do tipo de parto e os sentimentos negativos por parte das mães durante e após o parto.

Assim, as informações sobre o parto e o estímulo à prevalência da vontade das mulheres sobre as decisões médicas podem corresponder tanto ao maior conhecimento fisiológico sobre o processo de parturição como à maior satisfação em relação à escolha. É preciso, além disso, trabalhar o medo da dor do parto que foi socialmente construído e que estimula ainda mais a busca pelo parto sem dor. Nesse caso, a cesárea, normalmente, é o caminho mais "fácil".

Esse processo de busca da autonomia pode garantir maior envolvimento emocional entre mãe e bebê e a formulação de expectativas realistas sobre o parto, o que desencadeia maior preparação e participação da mãe nesse momento. Esses fatores são de extrema importância para a redução do mal-estar e das preocupações, que contribuem para deteriorar a qualidade e a experiência do parto (Costa et al., 2003).

\section{Expectativas de adolescentes nuligestas quanto às formas de parir}

O parto, normalmente, é representado pelas mulheres como um universo complexo de expectativas e idealizações. Essas expectativas compreendem o nascimento do filho e a assistência que a mulher irá receber na hora do parto. Dessa forma, como pano de fundo dessa representação, existe uma construção social que é sedimentada ao longo da vida pelas diversas fontes de informações sobre o processo de parturição, com evidências para as dores do parto, o momento da expulsão fetal, o choro do bebê ao nascer e a saúde deste. De acordo com Wolff (2004), essa construção social é reforçada pela mídia, que trata o parto como algo doloroso, exibindo cenas escandalosas com sangue e gritos e assim criando nas adolescentes uma imagem negativa sobre o parto.

Neste sentido, verificou-se que os relatos das adolescentes acerca das escolhas do tipo de parto têm ligação com as dores que provavelmente sentirão: "Cesáreo. Porque eu acho que a pessoa não sente nada!" (Adolescente 1) "Cortando a barriga, porque tem menos dor. A mãe da minha amiga teve bebê normal e disse que sentia muita dor, que na hora que puxa o bebê a dor é grande! Eu quero é uma cesárea!" (Adolescente 10)

Desse modo, percebe-se que as concepções das adolescentes (principalmente das primigestas e das que ainda não engravidaram) acerca do parto estão intrinsecamente relacionadas com as experiências das mulheres de sua rede de relações. Alguns aspectos como dor e sofrimento sempre são referidos e temidos quando se fala sobre o parto vaginal. Existe o mito/estigma de que este tipo de parto é arriscado para mãe e o bebê, levando a muita dor, desconforto e, ainda, de que pode prejudicar a anatomia da vagina para as relações sexuais. Seria interessante um trabalho que contribuísse para a desconstrução dessa ideia de dor insuportável, preparando melhor a mulher para o processo de parturição.

Estes aspectos contribuem para que as mulheres fiquem receosas quanto ao parto normal e acabem preferindo a cesariana. Lopes, Donelli, Lima, \& Piccinini (2005) acrescentam que, entre outros motivos, as mulheres preferem o parto cesáreo por acreditarem que esta forma de parir proporciona conforto, redução do sofrimento e maior segurança para o recém-nascido e que não interfere na vida sexual futura. Destarte, além da perspectiva de segurança para a mulher, existem também as questões estéticas que permeiam essa escolha.

Além das informações repassadas entre os pares acerca do parto como um processo extremamente traumatizante e doloroso, a falta de orientações adequadas faz aumentarem os medos e as angústias da mulher, que relaciona a forma vaginal de parir ao sofrimento. 
Sendo assim, apesar de ser inerente ao processo de parto, a dor também recebe influência de fatores sociais e culturais (Helman, 2009). É por isso que estas adolescentes, mesmo ainda não tendo passado pela experiência do parto, acabam tendo receio quanto ao parto vaginal, o que pode prejudicar a escolha acerca do seu tipo de parto em um futuro, caso elas não recebam as orientações adequadas. Diante desta situação, as adolescentes tendem a reproduzir os discursos de outras figuras femininas de sua convivência, passando a ter as mesmas opiniões sobre as formas de parir e nascer.

Por outro lado, algumas adolescentes demonstraram preferência pelo parto normal, utilizando o discurso acerca da rápida recuperação da mãe: "Normal. Porque a mulher quando é operada demora que só para se recuperar, tem que ficar deitada!" (Adolescente 8) "Normal. Porque só ia doer naquela hora, depois fica boa logo!" (Adolescente 12)

Por outro lado, apesar de admitirem a preferência pelo parto normal, ficou evidente que o conhecimento em que se baseou a escolha por esse tipo de parto não estava bem claro para essas adolescentes: "Mulher eu acho que eu prefiro normal. Porque assim... o povo diz que é melhor, né?" (Adolescente 11)

A partir desse relato, percebe-se que as adolescentes se baseiam em ideias relacionadas às informações repassadas pelo senso comum: a necessidade de uma recuperação mais rápida e o desejo de não sentir dor, e não têm argumentos fundamentados para preferirem a forma natural de parir.

Além disso, é importante destacar que, muitas vezes, a escolha pelo parto cirúrgico tem como causa o medo da dor no parto, condição que faz parte do imaginário de muitas mulheres ao pensarem na forma vaginal de ter um filho. O parto vaginal dói realmente, mas a fisiologia do corpo permite que essa dor venha acompanhada de um posterior relaxamento e liberação de endorfinas que permitem à mulher se sentir muito bem após o período expulsivo. Assim, apesar da dor temporária, o parto vaginal pode ser bem mais confortável para a mulher. O problema é que o processo de medicalização e a atual tendência de evitar dor e sofrimento a qualquer custo contribuem para a manutenção desse estigma. É preciso um trabalho de discussão sobre essas questões, não somente informação sobre os aspectos fisiológicos do parto.

É sabido que o parto cirúrgico foi concebido como um procedimento a ser realizado apenas diante de determinadas intercorrências clínicas, mas na atualidade esse procedimento tem sido realizado de forma agendada, sendo desconsiderada a sua real indicação (Mandarino, 2008). Neste sentido, os profissionais da saúde acabam se destacando na potencialização dos sujeitos em face das suas escolhas. A equipe de saúde, geralmente detentora dos saberes científicos relacionados à questão do parto, precisa atuar junto à comunidade realizando as orientações pertinentes à temática, dando ênfase aos benefícios do parto natural para a mãe e o filho.

As mulheres, independentemente da condição gestacional, devem ser orientadas na escolha do melhor tipo de parto. Para tanto, devem conhecer as vantagens do parto vaginal, que é o procedimento natural. Ademais, este tipo de procedimento exige menos intervenção médica e menor permanência no internamento, geralmente não tem contraindicações, é de menor risco de infecções para a mãe e o filho, estimula o funcionamento do corpo do bebê, é de menos risco de desconforto pulmonar após o parto e contribui para um retorno precoce às atividades diárias (Bezerra \& Cardoso, 2006).

\section{CONSIDERAÇÕES FINAIS}

A ocorrência de uma gestação ainda na adolescência tende a ser considerada um problema de saúde pública, pela possibilidade de acarretar dificuldades biológicas, sociais e psicológicas para a adolescente, seu filho e toda a família. Não obstante, é preciso levar em conta que não necessariamente todas as situações de gestação nessa faixa etária são problemáticas e, menos ainda, consideradas indesejáveis. A forma de organização da sociedade, com a valorização da família, contribuiu para a construção do desejo da maternidade no imaginário das adolescentes. Nessa dimensão, muitas gestações podem acontecer por desejo dos atores e ainda não representar intercorrências de nenhuma ordem.

Mesmo assim, independentemente do quererem ou não, para muitas adolescentes a situação de gravidez pode ser cercada de estigmas relacionados ao momento do parto, aos cuidados com os bebês, entre outros. Embora haja discussões e propostas para a redução do número de gestações na adolescência, poucos estudos denotam a importância de conhecer as preferências/conhecimentos destas jovens mães quanto às formas de parir e nascer.

Apreender de que forma o conhecimento acerca da escolha do tipo de parto é formado nas adolescentes é essencial para gerar um processo de reflexão sobre a forma de assistência que estamos promovendo nos serviços de saúde no país. Sabe-se 
que o Brasil apresenta elevadas taxas de cesarianas. A OMS vem tentando reduzir essas taxas a fim de atingir os $15 \%$ recomendados para as práticas de maternidade segura.

$\mathrm{O}$ interesse em investigar esse tema surge a partir da premissa de que as jovens, quando adequadamente trabalhadas antes de uma gestação, tornam-se protagonistas da escolha de seu próprio processo de parturição. Essa assertiva justifica-se pelo fato de elas estarem mais conscientes dos riscos e benefícios das diferentes formas de parir e nascer. Neste sentido, trabalhar nessa perspectiva aponta a necessidade de refletir acerca de ideias previamente concebidas, numa perspectiva de repensar as práticas existentes para favorecer a reorganização das ações desenvolvidas pelos profissionais de saúde destinadas às mulheres e, em particular, às adolescentes.

Os resultados deste estudo demonstraram que os conhecimentos das adolescentes acerca dos tipos de parto são restritos, em virtude da precariedade de informações - que são obtidas geralmente por meio das mães, da escola e das amigas - bem como dos mitos existentes sobre o parto.

Constatou-se, ainda, a forte influência cultural nos saberes das adolescentes sobre gestação e parto. Não possuindo a vivência destes eventos, elas tendem a reproduzir as opiniões das mulheres de sua rede de relações, ou seja, seus anseios sobre a forma de parir estão intrinsecamente relacionados aos comentários de quem já passou pela experiência.

Nenhuma das adolescentes entrevistadas admitiu ter recebido orientações de algum profissional da área da saúde, o que evidencia a carência de ações destinadas ao grupo jovem nas práticas de saúde naquela comunidade. Neste contexto, como a família é uma influente fonte de informação, cabe à equipe de saúde dos serviços da Atenção Básica prestar às famílias a devida orientação neste sentido, uma vez que está diariamente em contato com a comunidade e conhece de perto seu contexto social. É de fundamental importância que estes profissionais promovam atividades voltadas às famílias e às adolescentes, abordando diversas temáticas, entre elas a sexualidade. Trabalhando interdisciplinarmente, as equipes podem prestar esclarecimentos aos familiares e às próprias adolescentes, responder às suas inquietações e diminuir seus medos e receios, tornando-as protagonistas de suas próprias escolhas de vida.

Sugere-se que tais ações também possam, em alguns momentos, ser realizadas na escola, uma vez que neste espaço pode-se encontrar uma diversidade de alunos nesta faixa etária. Também é importante que os professores, supervisores, coordenadores e diretores sejam capacitados para assumir seu papel de educadores de maneira qualificada. Igualmente, tornase essencial a presença dos familiares nestas discussões, para que estes possam dar continuidade à educação de seus jovens fora do ambiente escolar.

Acredita-se que ações desta ordem poderão desmistificar os estigmas presentes em nossa sociedade a respeito do parto e permitir às adolescentes realizar escolhas conscientes sobre práticas médicas relativas a seus corpos.

\section{REFERÊNCIAS}

Almeida, H. (2008). A enfermeira no contexto da educação sexual dos adolescentes e o olhar da família. Dissertação de Mestrado, Programa de Pós-Graduação em Enfermagem, Universidade Federal do Paraná, Curitiba.

Barbosa, G. P., Giffin, K., Ângulo-Tuesta, A., Chor, D., D’Orsi, E., \& Reis, A. C. G. V. (2003). Parto Cesáreo: quem o deseja? Em quais circunstâncias? Caderno de Saúde Pública, 19(6), 1611-20.

Bezerra, M. G. A., \& Cardoso, M. V. L. M. L. (2006). Fatores culturais que interferem nas experiências das mulheres durante o trabalho de parto e parto. Revista LatinoAmericana de Enfermagem, 14(3), 414-21.

Biscoli, C., Favarão, N. R. L., Feiten, R. H., Souza, A. C. P., \& Perpétuo, C. L. (2005). Sexualidade em sala de aula: um estudo da produção de sentidos. Arquivo de Ciências $e$ Saúde Unipar, 9(1), 47-55.

Borges, A. L. V., Nichiata, L. Y. I., \& Schor, N. (2006). Conversando sobre sexo: a rede sociofamiliar como base de promoção da saúde sexual e reprodutiva de adolescentes. Revista Latino-Americana de Enfermagem, 14(3), 422-7.

Costa, R., Figueiredo, B., Pacheco, A., \& Pais, A. (2003). Parto: expectativas, experiências, dor e satisfação. Psicologia, Saúde \& Doenças, 4(1), 47-67.

D’Orsi, E., Chor, D., Giffin, K., Ângulo-Tuesta, A., Barbosa, G. P., Gama, A. S., \& Reis, A. C. G. V. (2006). Fatores associados à realização de cesáreas em uma maternidade pública no Município do Rio de Janeiro, Brasil. Caderno de Saúde Pública, 22(10), 2067-78.

Fontanella, B. J. B., Ricas, J., \& Turato, E. R. (2008). Amostragem por saturação em pesquisas qualitativas em saúde: contribuições teóricas. Caderno de Saúde Pública, 24(1), 17-27.

Fuchs, C. R. S. S. (2007). Sexo e sexualidade na adolescência: um assunto polêmico para os pais? Monografia, Curso de Psicologia, Universidade Vale do Itajaí, Itajaí.

Gama, A. S., Giffin, K. M., Angulo-Tuesta, A., Barbosa, G. P., \& D'Orsi, E. (2009). Representações e experiências das mulheres sobre a assistência ao parto vaginal e cesárea em maternidades pública e privada. Caderno de Saúde Pública, 25(11), 2480-2488. 
Heilborn, M. L., Salem, T., Rohden, F., Brandão, E., Knauth, D., Victora, C., Aquino, E., McCallum, C., \& Bozon, M. (2002). Aproximações socioantropológicas sobre a gravidez na adolescência. Horizontes antropológicos, 8(17), 13-45.

Helman, C. G. (2009). Cultura, saúde e doença (5a ed.). Porto Alegre: Artmed.

Instituto Brasileiro de Geografia e Estatística. (2009). Indicadores Sociodemográficos e de Saúde no Brasil. Rio de Janeiro: Autor.

Lopes, R. C. S., Donelli, T. S., Lima, C. M., \& Piccinini, C. A. (2005). O antes e o depois: expectativas e experiências de mães sobre o parto. Psicologia: Reflexão e crítica, 18(2), 247- 54.

Lupton, D. (1997). The imperative of public health: public health and the regulated body. London: Sage Publications.

Maia, A. C. B. (1998). Informações sobre temas relativos à sexualidade em um grupo de adolescentes de uma escola pública de Bauru - SP. Mimesis, 19(1), 41-58.

Mandarino, N. R. (2008). Aspectos relacionados à escolha do tipo de parto: um estudo comparativo entre uma maternidade pública e outra privada, em São Luís, Maranhão. Dissertação de Mestrado, Programa de PósGraduação em Saúde Materno-Infantil da Universidade Federal do Maranhão, São Luís.

Merighi, M. A. B., \& Gualda D. M. R. (2009). O cuidado a saúde materna no Brasil e o resgate do ensino de obstetrizes para assistência ao parto. Revista Latino-Americana de Enfermagem, 17(2), 265-70.

Ministério da Saúde. (2001). Parto aborto e puerpério: assistência humanizada à mulher. Brasília, DF: Autor.

Ministério da Saúde. (2002). Humanização do parto: humanização no pré-natal e nascimento. Brasília, DF: Autor.

Ministério da Saúde. (2004). Política Nacional de Atenção Integral à Saúde da Mulher: Princípios e Diretrizes. Série C. Projetos, Programas e Relatórios. Brasília, DF: Autor.

Morais, F. R. R. (2010). A humanização no parto e no nascimento: os saberes e as práticas no contexto de uma maternidade pública brasileira. Tese de Doutorado,
Programa de Pós Graduação em Psicologia Social, Universidade Federal do Rio Grande do Norte, Natal.

Organização Mundial de Saúde. (1996). Assistência ao parto normal: um guia prático. Genebra: Autor.

Sodré, T. M., Bonadio, I. C., Jesus, M. C. P., \& Merighi, M. A. B. (2010). Necessidade de cuidado e desejo de participação no parto de gestantes residentes em Londrina-Paraná. Texto Contexto Enfermagem, 19(3), 452-60.

Surtees, R. (2010). 'Everybody expects the perfect baby... and perfec labour... and so you have to protect yourself': discourses of defence in midwifery practice in Aotearoa/New Zealand. Nursing Inquiry, 17(1), 82-92.

Tesser, C. D. (2010). A atenção à saúde na construção cotidiana da cultura e da medicalização social. In: Tesser, C. D. (Org.) Medicalização Social e atenção à saúde no SUS. São Paulo: Hucitec.

Vieira, E. M. (2002). A medicalização do corpo feminino. Rio de Janeiro: Fiocruz.

Weinfurter L. T. (2008). Dimensões da territorialidade da saúde: estudo do movimento da humanização do parto na região da amplanorte. Dissertação de mestrado, Programa de Mestrado em Desenvolvimento Regional, Universidade do Contestado, Canoinhas.

Wolff, L. R. (2004). Representações sociais de mulheres sobre assistência no trabalho de parto e parto. Tese de doutorado, Programa de Pós-Graduação em Enfermagem da Escola de Enfermagem Anna Nery, Universidade Federal do Rio de Janeiro, Rio de Janeiro.

Recebido em 16/08/2011 Aceito em 20/06/2012

\section{Endereço para correspondência:}

Fátima Raquel Rosado Morais. Rua Frei Miguelinho 1137, Residencial Manoel Negreiros Apto 103B, Doze Anos, CEP 59603-350, Mossoró-RN, Brasil. E-mail: frrm@ bol.com.br. 